\title{
The effects of fulvestrant treatment on hormone receptor-positive metastatic breast cancer
}

\author{
Serdar Arıcı ${ }^{1} \odot$, Çağlayan Geredeli ${ }^{1} \odot$, Şaban Seçmeler ${ }^{1} \odot$, Abdullah Sakin $^{2} \odot,{\text { Orçun } \text { Can }^{3} \odot, \text { Nurgül }}^{\circ}$ \\ Yaşar $^{1} \odot$, Şener $\operatorname{Cihan}^{1} \odot$
}

${ }^{1}$ Department of Medical Oncology, University of Health Sciences, Okmeydanı Training and Research Hospital, Istanbul, Turkey ${ }^{2}$ Department of Medical Oncology, Yüzüncü Yil School of Medicine, Van, Turkey

${ }^{3}$ Department of Medical Oncology, Nevşehir State Hospital, Nevşehir, Turkey

\begin{abstract}
Objectives: To determine fulvestrant efficacy and tolerability in Turkish patients with hormone receptor-positive metastatic breast cancer.

Methods: Patients who developed metastasis while taking tamoxifen or aromatase inhibitors in the adjuvant period or metastatic disease at the diagnosis. Fulvestrant $500 \mathrm{mg}$ was administered intramuscularly every 28 days. Progression-free survival (PFS) and overall survival (OS) durations were calculated.

Results: In this particular research, totally 137 patients were participated. Median PFS was 9 months (95\% CI, 5.7-10.3). The 12-month PFS rate was calculated as 42\%, and the 36-month PFS rate was $17 \%$. The median PFS was not reached in the first line use of fulvestrant in the metastatic period but 9 months and 7 months in the second and subsequent lines respectively. Results indicated that this difference was statistically significant $(p=0.002)$. It was shown that patients with liver and brain metastasis had lower PFS compared patients with no liver and no brain metastasis. The estimated median OS was 38 months after fulvestrant started. The 12month OS rate was calculated as $82.4 \%$, and the 36 -month OS rate was $50 \%$.

Conclusions: Fulvestrant contributes both PFS and OS in patients with hormone receptor-positive metastatic breast cancer and this effect is more clear in using fulvestrant as first-line treatment.

Keywords: fulvestrant, breast cancer, endocrine treatment
\end{abstract}

$\mathrm{E}$ ndocrine therapy has preferred a form of treatment for hormone receptor (HR) positive early stage breast cancer and advanced stage breast cancer. Endocrine therapy agents that are not cross-resistant to sequential administration prolong the chemotherapy-free period and have limited toxicity-effective disease stabilization. Tamoxifen has been the backbone of endocrine therapy for almost the last 30-40 years. In metastatic disease, response rate increases up to approximately $30 \%$ by using tamoxifen [1-3]. Tamoxifen and its metabolites are linked to the estrogen receptor
(ER) and this receptor modulation also causes the antagonistic effect as an estrogenic effect [4]. Another group of drugs used in endocrine therapy is aromatase inhibitors (AI). In randomized clinical trials, AI was superior to tamoxifen in postmenopausal women [1, 3]. Fulvestrant, a 17 beta-estradiol analog, is a selective ER antagonist that suppresses estrogen signaling by binding to ER and inducing a conformational change $[5,6]$. Dimerization is subsequently blocked, triggering accelerated degradation and downregulation of the ER protein [5]. Fulvestrant exhibits lack of 
cross-reactivity with tamoxifen. The clinical efficacy of fulvestrant was initially demonstrated in two phases III trials that compared fulvestrant $250 \mathrm{mg}$ per month with anastrozole $1 \mathrm{mg}$ daily as a secondline therapy for advanced breast cancer [7, 8]. A combined analysis of these trials demonstrated that time to progression (TTP) with fulvestrant $250 \mathrm{mg}$ was noninferior to anastrozole [9]. The phase III CONFIRM trial found that fulvestrant $500 \mathrm{mg}$ was associated with improved progression-free survival (PFS) and overall survival (OS) compared with the $250 \mathrm{mg}$ dose in patients who experienced disease recurrence or progression after previous endocrine therapy $[10,11]$. The FIRST study reported that improved OS with fulvestrant $500 \mathrm{mg}$ treatment compared with anastrozole in the first-line setting for ER-positive advanced breast cancer, with an approximately $30 \%$ reduction in mortality risk [12] In this retrospective study, we investigated fulvestrant efficacy and tolerability in Turkish patients with hormone receptor-positive metastatic breast cancer.

\section{METHODS}

This study was planned as a retrospective single center study. Istanbul Okmeydanı Training and Research Hospital obtained medical information from the archive files of patients who were treated with hormone receptor positive and HER 2 negative metastatic breast cancer in the medical oncology clinic. Patients who developed metastasis while taking tamoxifen or aromatase inhibitors in the adjuvant period or metastatic disease at the diagnosis. Fulvestrant $500 \mathrm{mg}$ was administered intramuscularly every 28 days (500 $\mathrm{mg}$ loading after 14 days from the first dose). PFS and OS durations were calculated by obtaining the date of starting Fulvestrant treatment, date of progression and date of the last visit from patient files.

\section{Statistical Analysis}

SPSS 15.0 for Windows program was used for statistical analysis. Comparisons of ratios in groups were made with Chi Square Analysis. Monte Carlo simulation was applied when conditions were not met. The survival analyzes were performed with Kaplan Meier Analysis. A statistical significance level of alpha was accepted as $p<0.05$.

\section{RESULTS}

In this particular research, totally 137 patients were participated. The median age was 53 (min.: 27 max.: 91). The median follow-up time was 20 months (0-78 months). $20.9 \%$ patients were metastatic stage at the diagnosis. $22 \%$ of patients had not received any endocrine treatment before fulvestrant (Table1). During the follow-up period, $65 \%$ of the patients developed progression, $35 \%$ had no progression and still continued to use Fulvestant. Median PFS was 9 (95\% CI 5.7-10.3) months (Figure 1). The 12-month PFS rate was calculated as $42 \%$, and the 36-month PFS rate was $17 \%$ (Table 2). The median PFS was not reached in the first line use of fulvestrant in the metastatic period but 9 months and 7 months in the second and subsequent lines respectively. Results indicated that this difference was statistically significant $(p=0.002)$ (Table-3). There was no significant difference in PFS according to age, hormone and cerb-2 status in subgroup analyzes. It was clear that patients with liver and brain metastasis had lower PFS compared patients with no liver and no brain metastasis, the median PFS in patients with liver metastasis was 6 months (no liver metastasis 11 months) and in patients with brain metastasis was 3 months (no brain metastasis 10 months) these differences were statistically significant ( $p=0.004$ and $p=0.011$ respectively in patients liver metastasis and brain metastasis). But PFS in patients with bone or lung or lymph node metastasis not statistically significant difference compared patients with no metastasis at these sites $(p=0.235, p=0.632$ and $p=$ 0.156 respectively) (Table-4). The estimated median OS was 38 months after fulvestrant started. The 12month OS rate was calculated as $82.4 \%$, and the 36-month OS rate was 50\%. 12-month (Table 5). OS rate was $95 \%$ in the first line use of fulvestrant in the metastatic period but $81.8 \%, 82.6 \%, 75.5 \%$ in the second, third and fourth line respectively. But this difference was not statistically significant $(p=0.149)$. Also median OS, in patients using fulvestrant as firstline, was 48 months (Table 6). In subgroup analyzes, there was a statistically significant OS difference in patients with liver metastasis compared with patients had no liver metastasis, the median OS was 18 months and 52 months respectively $(p=0.049)$. Also in patients with brain metastasis compared with patients 
Table 1. Patient Characteristics

\begin{tabular}{lccc}
\hline & & Mean \pm SD & Min-Max \\
\hline Age (years) & & $53.0 \pm 13.4$ & $27-91$ \\
& & & \\
& & & \\
\hline Menopause & Post & 69 & 51.1 \\
& Pre & 66 & 48.9 \\
\hline Hystology & & & \\
& Ductal & 119 & 87.5 \\
\hline Adjuvant ET & Lobular & 13 & 9.6 \\
& Others & 4 & 2.9 \\
\hline Nollow-up time (months) & No & 28 & 22.0 \\
\hline & Tamoxifen & 61 & 48.0 \\
\hline Metastasis at diagnosis & Tamoxifen+anastrazole & 24 & 18.9 \\
\hline Metastasis site at starting fulvestrant & Tamoxifen+letrozole & 14 & 11.0 \\
& & 27 & 20.9 \\
& Bone & 102 & 74.5 \\
\hline & Lymph nodes & 27 & 19.7 \\
\hline & Liver & 24 & 17.5 \\
\hline & Lung & 33 & 24.1 \\
\hline & Brain & 3 & 2.2 \\
\hline & Others & 9 & 6.6 \\
\hline & & $20.0 \pm 14.9(0-78)$ \\
\hline
\end{tabular}

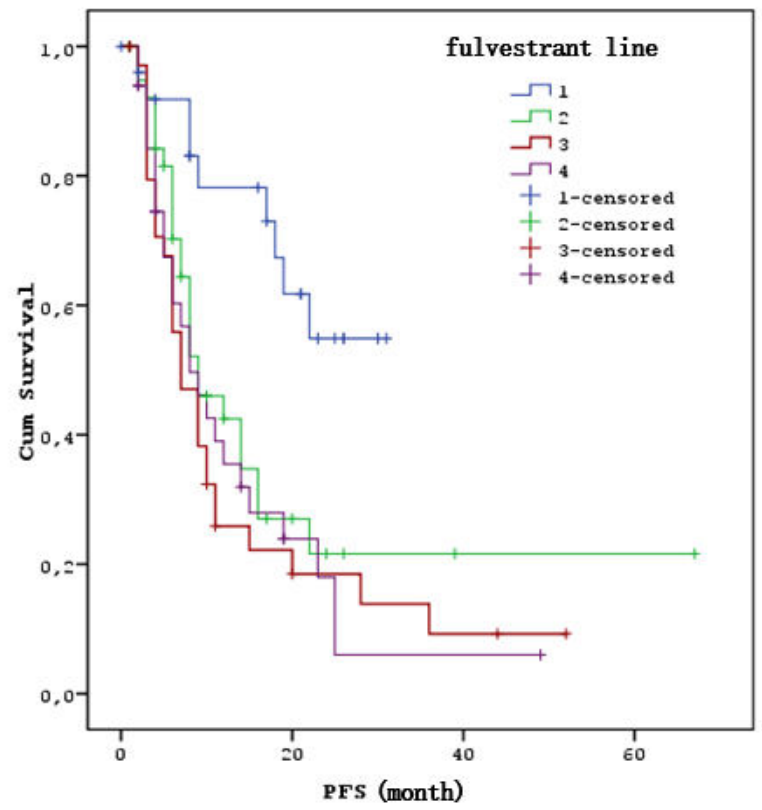

Fig. 1. Cumulative proportion surviving. $\mathrm{PFS}=$ progression free survival. 
Table 2. Progression free survival

\begin{tabular}{lcc}
\hline & & PFS \\
\hline Estimate median for PFS (95\% CI) month & & $9(6.8-11.2)$ \\
Cumulative proportion surviving (\%) & 12 & 42.4 \\
& 24 & 26.0 \\
& 36 & 17.1 \\
\hline
\end{tabular}

$\mathrm{PFS}=$ progression free survival

Table 3. Fulvestrant line and PFS

\begin{tabular}{lccccc}
\hline & & & \multicolumn{3}{c}{ Cumulative Proportion Surviving (\%) } \\
\hline \multirow{2}{*}{ Fulvestrant line } & 1 & Median (\%95 CI) & 12. month & 24. month & 36. month \\
& 2 & Not reached & 78.2 & 54.9 & - \\
& 3 & $9(5.2-12.8)$ & 42.5 & 21.6 & \\
Log Rank $p$ & 4 & $8(4.1-9.9)$ & 25.9 & 18.5 & 9.2 \\
\hline
\end{tabular}

$\mathrm{PFS}=$ progression free survival

Table 4. Site of metastasis and PFS-OS

\begin{tabular}{llcccc}
\hline Site & & $\begin{array}{c}\text { Median } \\
\text { PFS }\end{array}$ & $\begin{array}{c}\text { Median } \\
\text { OS }\end{array}$ & $\begin{array}{c}\text { OS } \\
\boldsymbol{p} \text { value }\end{array}$ & $\begin{array}{c}\text { PFS } \\
\boldsymbol{p} \text { value }\end{array}$ \\
\hline Bone & no & 9 & 52 & 0.818 & 0.235 \\
& yes & 10 & 35 & & \\
\hline Lymph & no & 11 & 38 & 0.646 & 0.156 \\
& yes & 7 & 77 & & 0.004 \\
\hline Liver & no & 11 & 52 & 0.049 & 0.632 \\
& yes & 6 & 18 & & \\
\hline Lung & no & 9 & 35 & 0.936 & 0.011 \\
\hline Brain & yes & 9 & 52 & & \\
\hline
\end{tabular}

$\mathrm{OS}=$ overall survival, $\mathrm{PFS}=$ progression free survival

\section{Table 5. Overall survival}

\begin{tabular}{lcc}
\hline & & OS \\
\hline Estimate Median for Survival Time (\%95 CI) & month & 38 (17.1-58.9) \\
Cumulative Proportion Surviving (\%) & 12 & 82.4 \\
& 24 & 61.5 \\
& 36 & 50.5 \\
\hline OS = overall survival & 60 & 40.2 \\
\hline
\end{tabular}


Table 6. Cumulative proportion surviving

\begin{tabular}{lcccc}
\hline & \multicolumn{3}{c}{ Cumulative Proportion Surviving (\%) } \\
\hline \multirow{2}{*}{ Fulvestrant line } & 1 & Median (95\% CI) & 12. month & 36. month \\
& 2 & 48 & 95.0 & 79.8 \\
& 3 & $27(0-60.3)$ & 81.8 & 46.5 \\
& 4 & $26(15.2-36.5)$ & 75.6 & 45.9 \\
Log Rank $p$ & & 0.149 & 46.1 \\
\hline
\end{tabular}

had no brain metastasis, the median OS was significantly lower (12 months and 38 months respectively, $p=0.001$ ) (Table 4 ). In all patients, toxic effects such as myalgia, arthralgia, fever and bone complications were observed in $23.9 \%$ of the patients and grade 3-4 toxic effect was not observed.

\section{DISCUSSION}

This particular research was a retrospective study that had been analyzed the clinical outcomes of fulvestrant treatment in post-menopausal patients with advanced breast cancer. It is found that median PFS had been 9 months. In two studies on Japanese women with advanced breast cancer treated with fulvestrant were reported that PFS was 5.4-5.5 months [13, 14]. In another study by Ishida et al. [15], fulvestrant in Japanese women with metastatic breast cancer that progressed after endocrine therapy was found that the median time to progression was 6.1 months.

In CONFIRM study, the median PFS was 6.5 months. In this study, fulvestrant treatment had been only located in the second line [10]. In this study there had been patients treating with fulvestrant first to the fourth line, but approximately $50 \%$ of patients were in the first line group. In this study trial, The median PFS had not reached in the first line use of fulvestrant in the metastatic period but 9 months and 7 months in the second and subsequent lines respectively $(p=0.002)$.

In the univariate analysis of this particular study found a lower PFS, regarding the presence-absence of liver and or brain metastasis. Similarly, FALCON study reported that in the presence of visceral disease PFS was significantly lower [16]. Kawaguchi et al.
[13] found a similar PFS in the presence or absence of visceral disease. In contrast to the results found in this study and the FALCON study sub-analysis, a metaanalysis by Graham et al. [17] of four randomized controlled trials found that fulvestrant was associated with greater benefit in advanced breast cancer patients with visceral metastasis.

The estimated median OS was 38 months after fulvestrant started, in this particular study. The FIRST study was eveluated overall survival of patients who were postmenopausal women with estrogen receptorpositive, locally advanced/metastatic breast cancer who had no previous therapy for advanced disease received either fulvestrant $500 \mathrm{mg}$ (days $0,14,28$, and every 28 days thereafter) or anastrozole $1 \mathrm{mg}$ (daily). The median OS was reported 54.1 months in the FIRST study [12]. But in the FACT trial, the median OS was 37.8 months in patients receiving fulvestrant plus anastrazole. The patients in FACT trial was received fulvestrant and anastrazole in first-line at metastatic disease but fulvestrant was used $250 \mathrm{mg}$ [18]. In our trial, aproximately half of patients have used fulvestrant at second and further lines and median OS, in patients using fulvestrant as first-line, was 48 months.

In the FIRST study, $70.1 \%$ of patients experienced at least one adverse effects; the incidence of serious adverse effects was $11.9 \%$ with fulvestrant [12]. In the FALCON trial, $73 \%$ of patients in the fulvestrant group reported the adverse event and serious adverse events were reported by $13 \%$. The most common side effects were arthralgia [17]. In our retrospective study, toxic effects such as myalgia, arthralgia, fever and bone complications were observed in $23.9 \%$ of the patients and grade 3-4 toxic effect was not observed. 


\section{CONCLUSION}

In conclusion, fulvestrant contributes both PFS and OS in patients with hormone receptor-positive metastatic breast cancer and this effect is more clear in using fulvestrant as first-line treatment.

\section{Conflict of interest}

The authors disclosed no conflict of interest during the preparation or publication of this manuscript.

\section{Financing}

The authors disclosed that they did not receive any grant during conduction or writing of this study.

\section{REFERENCES}

1. Bonneterre J, Buzdar A, Nabholtz JM, Robertson JF, Thürlimann B, von Euler M, et al. Anastrozole is superior totamoxifen as first-line therapy in hormone receptor positive advanced breast carcinoma. Cancer 2001;92:2247-58.

2. Bajetta E, Procopio G, Ferrari L, Martinetti A, Zilembo N, Catena L, et al. A randomized, multicenter prospective trial assessing long-acting release octreotide pamoate plus tamoxifen as a first line therapy for advanced breast carcinoma. Cancer 2002;94:299-304.

3. Paridaens R, Dirix L, Lohrisch C, Beex L, Nooij M, Cameron $\mathrm{D}$, et al. Mature results of a randomized phase II multicenter study of exemestane versus tamoxifen as first-line hormone therapy for postmenopausal women with metastatic breast cancer. Ann Oncol 2003;14:1391-8.

4 Dutertre M, Smith CL. Molecularmechanisms of selectiveestrogenreceptormodulator (SERM) action. J Pharmacol Exp Ther 2000;295:431-7.

5. Wakeling AE, Dukes M, Bowler J. A potent specific pure antiestrogen with clinical potential. Cancer Res 1991;51:386773.

6 Wakeling AE. Similarities and distinctions in the mode of action of different classes of antioestrogens. Endocr Relat Cancer 2000;7:17-28.

7. Osborne CK, Pippen J, Jones SE, Parker LM, Ellis M, Come $\mathrm{S}$, et al: Double-blind, randomized trial comparing the effi- cacy and tolerability of fulvestrant versus anastrozole in postmenopausal women with advanced breast cancer progressing on prior endocrine therapy: Results of a North American trial. J Clin Oncol 2002;20:3386-95. 8. Howell A, Robertson JFR, Quaresma Albano J, 2012;30:1919-25.
Aschermannova A, Mauriac L, Kleeberg UR, et al. Fulvestrant, formerly ICI 182,780 , is as effective as anastrozole in postmenopausal women with advanced breast cancer progressing after prior endocrine treatment. J Clin Oncol 2002;20:3396-403. 9. Robertson JFR, Osborne CK, Howell A, Jones SE, Mauriac L, Ellis M, et al. Fulvestrant versus anastrozole for the treatment of advanced breast carcinoma in postmenopausal women: A prospective combined analysis of two multicenter trials. Cancer 2003;98:229-38.

10. Di Leo A, Jerusalem G, Petruzelka L, Torres R, Bondarenko IN, Khasanov R, et al. Results of the CONFIRM Phase III trial comparing fulvestrant $250 \mathrm{mg}$ with fulvestrant $500 \mathrm{mg}$ in postmenopausal women with estrogen receptor- positive advanced breast cancer. J Clin Oncol 2010;28:4594-600.

11. Di Leo A, Jerusalem G, Petruzelka L, Torres R, Bondarenko IN, Khasanov R, et al. Final overall survival: fulvestrant $500 \mathrm{mg}$ vs $250 \mathrm{mg}$ in the randomized CONFIRM trial. J Natl Cancer Inst 2014;106:djt337.

12. Ellis MJ, Llombart-Cussac A, Feltl D, Dewar JA, Jasiówka M, Hewson N, et al. Fulvestrant $500 \mathrm{mg}$ versus anastrozole $1 \mathrm{mg}$ for the first-line treatment of advanced breast cancer: overall survival analysis from the phase II FIRST study. J Clin Oncol 2015;33:3781-7.

13. Kawaguchi H, Masuda N, Nakayama T, Aogi K, Anan K, Ito $\mathrm{Y}$ et al. Outcomes of fulvestrant therapy among Japanese women with advanced breast cancer: a retrospective multicenter cohort study (JBCRG-C06; Safari). Breast Cancer Res Treat 2017;163:545-54.

14. Araki K, Ishida N, Horii R, Takahashi S, Akiyama F, Ito Y, et al. Efficacy of fulvestrant $500 \mathrm{mg}$ in Japanese postmenopausal advanced/recurrent breast cancer patients and factors associated with prolonged time-to-treatment failure. Expert Opin Pharmacother 2015; 16:2561-8.

15. Ishida N, Araki K, Sakai T, Kobayashi K, Kobayashi T, Fukada I, et al. Fulvestrant $500 \mathrm{mg}$ in postmenopausal patients with metastatic breast cancer: the initial clinical experience. Breast Cancer 2016;23:617-23.

16. Robertson JFR, Bondarenko IM, Trishkina E, Dvorkin M, Panasci L, Manikhas A, et al. Fulvestrant $500 \mathrm{mg}$ versus anastrozole $1 \mathrm{mg}$ for hormone receptor-positive advanced breast cancer (FALCON): an international, randomised, double-blind, phase 3 trial. Lancet 2016;388:2997-3005.

17. Graham J, Pitz M, Gordon V, Grenier D, Amir E, Niraula S. Clinical predictors of benefit from fulvestrant in advanced breast cancer: a meta-analysis of randomized controlled trials. Cancer Treat Rev 2016;45:1-6.

18. Bergh J, Jönsson PE, Lidbrink EK, Trudeau M, Eiermann W, Brattström D, et al. FACT: an open-label randomized phase III study of fulvestrant and anastrozole in combination compared with anastrozole alone as first-line therapy for patients with receptor-positive postmenopausal breast cancer. J Clin Oncol 